\title{
Malignant Parotid Gland Neoplasm
}

National Cancer Institute

\section{Source}

National Cancer Institute. Malignant Parotid Gland Neoplasm. NCI Thesaurus. Code C3525.

A primary or metastatic malignant neoplasm involving the parotid gland. Representative examples include carcinoma, malignant mixed tumor, and non-Hodgkin lymphoma. 